\title{
Right Atrial Mass Imitating the Catheter
}

\author{
Aysu Oktay, Feyza Aksu, Mustafa Çaliskan \\ Department of Cardiology, Goztepe Training and Research Hospital, Istanbul Medeniyet University, Istanbul, Turkey \\ ORCID: \\ Aysu Oktay: 0000-0001-8988-5826 \\ Feyza Aksu: 0000-0002-1212-7127 \\ Mustafa Çaliskan: 0000-0001-7417-4001
}

\section{Abstract}

Catheter-related thrombosis is a relatively common complication of central venous catheter insertion. The catheter-related complications (malfunctions, infections, and thrombosis) cause serious problems in these patients. In patients presenting with fever and a history of venous catheterization, the right heart cavities and venous system should be carefully evaluated due to the procedure that may form a basis for infective endocarditis even if the catheter is removed. In this article, we report a case of right atrial mass mimicking a catheter in a patient with a history of recurrent venous catheterization due to hemodialysis.

Keywords: Catheter-related thrombosis, central venous catheterization, infective endocarditis

\section{INTRODUCTION}

Central venous catheterization could use for many different indications, such as intravenous drug therapy, hemodynamic monitorization, hemodialysis, parenteral support at the intensive care services, dialysis units, and other wards. ${ }^{[1]}$ Thrombosis and infection are the most common complications and increase in proportion to the duration of catheterization. ${ }^{[2]}$ Thrombosis is more common than expected but rarely presents with symptoms. In ultrasonographic evaluation, it is seen as plastered or mobile masses on the catheter.

In this article, we report a case of right atrial mass mimicking a catheter that developed in catheterization in a patient undergoing dialysis for familial Mediterranean fever and renal amyloidosis with multiple central venous catheterization attempts for dialysis.

\section{Case Report}

A 19-year-old female patient who had renal failure due to renal amyloidosis and admitted to hospital for dialysis treatment had a history of meningomyelocele, ventriculoperitoneal shunt, ureterostomy, and ileus.

Received: 05-11-2019 Revised: 30-12-2019 Accepted: 02-03-2020

Published Online: 11-06-2020

\begin{tabular}{|l|l|}
\hline \multicolumn{3}{|c|}{ Access this article online } \\
\hline Quick Response Code: & Website: \\
& \\
http://www.ijcva.com
\end{tabular}

The patient was consulted to cardiology with suspicion of endocarditis when there was a reproduction in blood culture and significant increasement at acute-phase reactants. Transthoracic echocardiographic examination showed an image of a $2.5 \mathrm{~mm} \times 1.7 \mathrm{~mm}$ thrombus-compatible mass image associated with the catheter that showed entry and exit into the right ventricle at diastole. Transesophageal echocardiography (TEE) showed that the mass was compatible with a thrombus and attached to the catheter tip with a handle [Figure 1]. Catheter infection was suspected at that time. After the thrombus regressed in response to the treatment of appropriate anticoagulant therapy and antibiotherapy, the catheter was removed. The patient started to treat with antibiotherapy, and then, she was discharged from the hospital with medical treatment. The patient undergoing dialysis had to undergo a temporary dialysis catheter through different peripheral veins until a fistula was formed. After 5 months, the patient came to the emergency department with a complaint of nausea, vomiting,

Address for correspondence: Dr. Feyza Aksu Department of Cardiology, Goztepe Training and Research Hospital, Istanbul Medeniyet University, Istanbul, Turkey. E-mail: feyzaulusoyaksu@yahoo.com

This is an open access journal, and articles are distributed under the terms of the Creative Commons Attribution-NonCommercial-ShareAlike 4.0 License, which allows others to remix, tweak, and build upon the work non-commercially, as long as appropriate credit is given and the new creations are licensed under the identical terms.

For reprints contact: WKHLRPMedknow_reprints@wolterskluwer.com

How to cite this article: Oktay A, Aksu F, Caliskan M. Right atrial mass imitating the catheter. Int J Cardiovasc Acad 2020;6:89-91. 
fever, and chills. Catheter infection was suspected at first sight. The hemodialysis catheter in the left femoral vein was removed; a temporary dialysis catheter was inserted through the right femoral vein. Piperacillin/tazobactam and daptomycin treatment was started. In consequence of isolation of Acinetobacter Baumannii from catheter culture and Staphylococcus Epidermidis from first and control blood cultures, a new TEE examination planned. Because second pathogen might involved in the etiology of infective endocarditis. At the TEE examination, an image of an immobile, irregularly contoured mass was seen in the right atrium without a catheter, adhering to the wall extending from the superior vena cava to a straight line toward the interatrial septum and inferior vena cava [Figure 2]. When the patient's previous radiological images were evaluated, it was observed that the dialysis catheter, which was inserted 2 months ago from the left subclavian vein and was used for a short time, was not suitable for the patient and that the mass image detected in the TEE was in line with the catheter line [Figure 3]. Therefore, it was thought that fibrin and

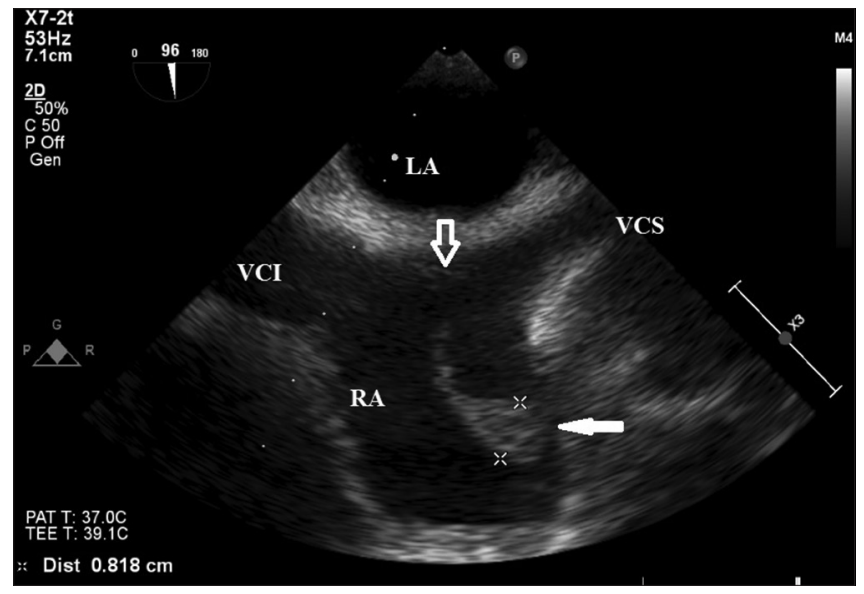

Figure 1: Transesophageal echocardiography bicaval image. LA = Left atrium; RA = Right atrium; $\mathrm{VCS}=$ Vena cava superior; $\mathrm{VCI}=$ Vena cava inferior; Blank arrow $=$ Catheter tip; Filled arrow $=$ Thrombus attached to the catheter tip with a handle

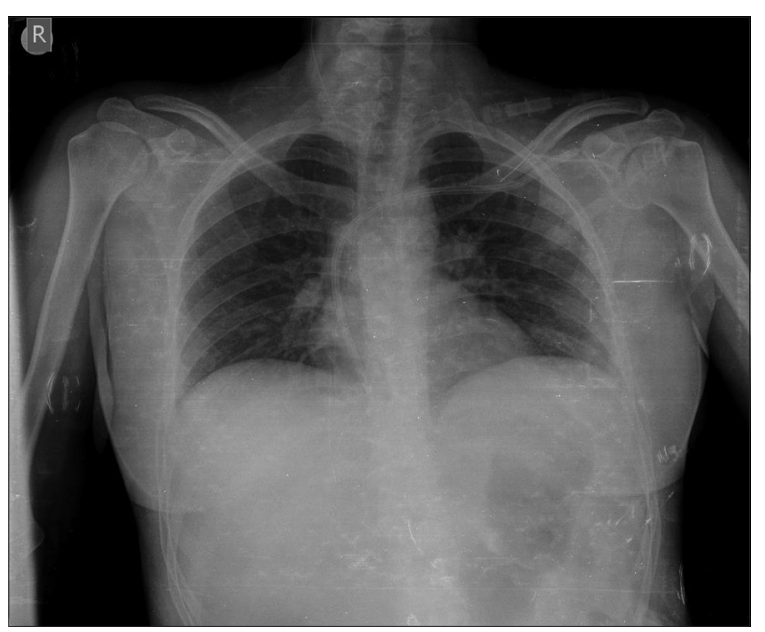

Figure 3: Anteroposterior lung radiography platelet accumulation following endothelial damage caused by catheter in the foreground provided a basis for infective endocarditis even if the catheter was removed.

Appropriate antibiotic and anticoagulant treatment was started. Control TEE was performed 4 weeks after clinical improvement, and no pathological finding was detected in the right atrium [Figure 4].

\section{Discussion}

The sensitivity and specificity of TEE in the thrombus is $100 \%$, whereas the sensitivity and specificity of transthoracic echocardiography in the thrombus is $95 \%$ and $86 \%$, respectively. ${ }^{[3,4]}$ Thrombi are smooth-edged, homogeneous, bright masses that tend to settle around the ventricular apex, atrial appendix, or catheter. When treatment-resistant infection develops in patients with a long history of central catheterization, patients should be evaluated for catheter-related thrombus. In the literature, it is seen that catheter-related thrombus/vegetation cases develop in the presence of the catheter. Although the catheter itself is thought

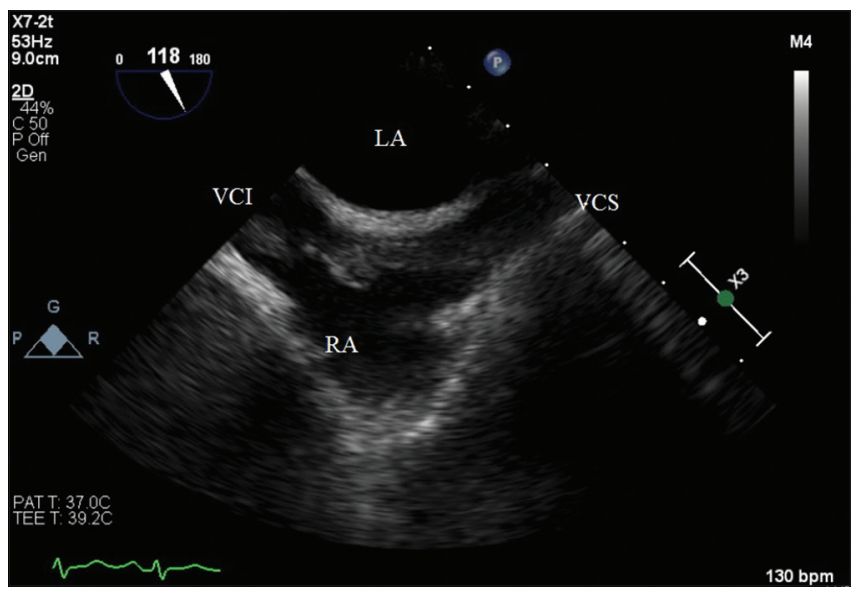

Figure 2: Transesophageal echocardiography bicaval image. LA = Left atrium; $\mathrm{RA}=$ Right atrium; $\mathrm{VCS}=$ Vena cava superior; $\mathrm{VCl}=$ Vena cava inferior

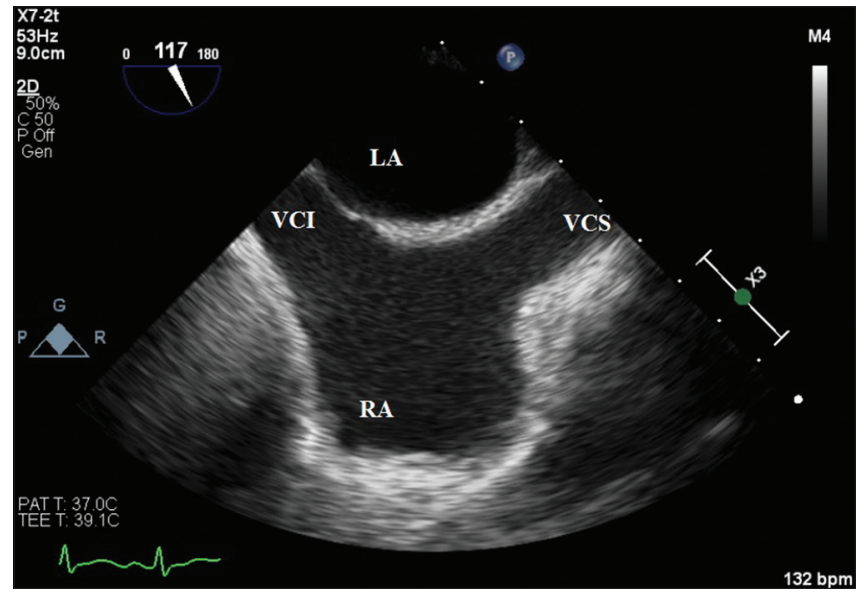

Figure 4: Transesophageal echocardiography bicaval image 
to be a cause for thrombus/vegetation, the pathogenesis is not fully understood. In the first $24 \mathrm{~h}$ after the catheter is inserted, a protein sheath consisting of inflammatory cells and collagen is formed on the catheter. ${ }^{[5-7]}$ With this fibrin sheath, the catheter surface becomes an irregular surface area where bacteria can settle more easily. Experimental studies showed that the sheath around the catheter started as a thrombus in the first few days and transformed into cell-rich collagen tissue and smooth muscle cells within 1-2 weeks. ${ }^{[8,9]}$ The fibrin sheath formed at the point of contact of the catheter to the vein may adhere to the vein wall over time. ${ }^{[9]}$

As a result, the remaining fibrin-thrombus sheath and endothelial damage due to the procedure may form a basis for infective endocarditis even if the catheter is removed. During the maturation of the arteriovenous fistula, which was opened due to the patient's chronic renal failure and hemodialysis patients, the adverse effects of the catheters inserted using a different venous system and the adverse effects of chronic renal failure on immunity were considered as the pathological major mechanism. ${ }^{[10]}$ In patients presenting with fever and a history of venous catheterization, the right heart cavities and venous system should be carefully evaluated. It is also appropriate to insert a central catheter tip inserted from the subclavian or jugular vein distally to the superior vena cava or to the junction of the right atrium-superior vena cava. For this reason, care should be taken to provide an appropriate-sized catheter to the patient before the procedure.

\section{Declaration of patient consent}

The authors certify that they have obtained all appropriate patient consent forms. In the form the patient(s) has/have given his/her/their consent for his/her/their images and other clinical information to be reported in the journal. The patients understand that their names and initials will not be published and due efforts will be made to conceal their identity, but anonymity cannot be guaranteed.

\section{Financial support and sponsorship}

Nil.

\section{Conflicts of interest}

There are no conflicts of interest.

\section{RefEREnCES}

1. Bourgeois SL Jr. Central venous access techniques. Atlas Oral Maxillofac Surg Clin North Am 2015;23:137-45.

2. Eisen LA, Narasimhan M, Berger JS, Mayo PH, Rosen MJ, Schneider RF. Mechanical complications of central venous catheters. J Intensive Care Med 2006;21:40-6.

3. Stratton JR, Lighty GW Jr, Pearlman AS, Ritchie JL. Detection of left ventricular thrombus by two-dimensional echocardiography: Sensitivity, specificity, and causes of uncertainty. Circulation 1982;66:156-66.

4. Manning WJ, Weintraub RM, Waksmonski CA, Haering JM, Rooney PS, Maslow AD, et al. Accuracy of transesophageal echocardiography for identifying left atrial thrombi. A prospective, intraoperative study. Ann Intern Med 1995;123:817-22.

5. Forauer AR, Theoharis CG, Dasika NL. Jugular vein catheter placement: Histologic features and development of catheter-related (fibrin) sheaths in a swine model. Radiology 2006;240:427-34.

6. Takahashi T, Minematsu T, Murayama R, Nakagami G, Mori T, Sanada H. Catheter tips are a possible resource for biological study on catheter failure. Drug Discov Ther 2019;13:280-7.

7. Lloyd DA, Shanbhogue LK, Doherty PJ, Sunderland D, Hart CA, Williams DF. Does the fibrin coat around a central venous catheter influence catheter-related sepsis? J Pediatr Surg 1993;28:345-8.

8. Hoshal VL Jr., Ause RG, Hoskins PA. Fibrin sleeve formation on indwelling subclavian central venous catheters. Arch Surg 1971;102:353-8.

9. Xiang DZ, Verbeken EK, Van Lommel AT, Stas M, De Wever I. Composition and formation of the sleeve enveloping a central venous catheter. J Vasc Surg 1998;28:260-71.

10. Fouque D, Kalantar-Zadeh K, Kopple J, Cano N, Chauveau P, Cuppari $\mathrm{L}$, et al. A proposed nomenclature and diagnostic criteria for protein-energy wasting in acute and chronic kidney disease. Kidney Int 2008;73:391-8. 